M 



\title{
Lexikon der
}

\section{Volkswirtschaftlichen} Gesamtrechnungen

\author{
Herausgegeben von \\ Prof. Dr. Dieter Brümmerhoff \\ Universität Rostock \\ Dipl.-Volksw. Heinrich Lützel \\ Vizepräsident des Statistischen Bundesamtes Wiesbaden
}

Dritte, völlig überarbeitete Auflage

R.Oldenbourg Verlag München Wien 


\section{Die Deutsche Bibliothek - CIP-Einheitsaufnahme}

Lexikon der volkswirtschaftlichen Gesamtrechnungen / hrsg. von Dieter Brümmerhoff; Heinrich Lützel. - 3., völlig überarb. Aufl.. München ; Wien : Oldenbourg, 2002

ISBN 3-486-25949-0

(C) 2002 Oldenbourg Wissenschaftsverlag GmbH

Rosenheimer Straße 145, D-81671 München

Telefon: (089) 45051-0

www.oldenbourg-verlag.de

Das Werk einschließlich aller Abbildungen ist urheberrechtlich geschützt. Jede Verwertung außerhalb der Grenzen des Urheberrechtsgesetzes ist ohne Zustimmung des Verlages unzulässig und strafbar. Das gilt insbesondere für Vervielfăltigungen, Übersetzungen, Mikroverfilmungen und die Einspeicherung und Bearbeitung in elektronischen Systemen.

Gedruckt auf săure- und chlorfreiem Papier

Gesamtherstellung: Druckhaus „Thomas Müntzer“ GmbH, Bad Langensalza 